\title{
The Significance of Research Methods with Reference to Language Education in Higher Education
}

\author{
Ismail Noriey \\ Department of English, College of Languages, University of Human Development, Sulaimani, Kurdistan Region - F.R. Iraq
}

\begin{abstract}
This research paper investigates the significance of research in language education in the higher education sector. For this purpose, the researcher conducted a case study with twenty $4^{\text {th }}$ year students studying English at the University of Human Development (UHD), Iraqi Kurdistan Region. They were selected based on purposive sampling. The participants were invited to respond to a questionnaire that was created and piloted by the researcher. They were also requested to take part in a structured interview. The findings show that the nature of research methods for $4^{\text {th }}$ year students across higher education is complex and elusive. The findings also show that most of the students almost have the same problems and they have similar views on their final project as they started at the beginning of the final year of the academic year (2018-2019) at the University of Human Development.
\end{abstract}

Index terms-Research methods, Reference to language, positivism, post-positivism, interpretivism, epistemology, ontology.

\section{INTRODUCTION}

This research paper investigates the significance of research methods in language education within higher education and explores the epistemological aspect of social science. It is divided into three main sections. The first focuses on; establishing the justification of the topic as educational research methods in Higher Education (HE) in Iraqi Kurdistan, by arguing that the concepts of the ontology and epistemology and their understanding of theoretical assumptions in research methods. The researcher has justified the choice of methodologies and methods. According to Crotty (1998, p.64) the justification of the choice and use of methodology; plan of action, strategy, design lying behind the use of particular methods and the methods; techniques and analyze data related to the research questions addressed. This allows the researcher to gain an understanding of the research problems and the importance of the study in the field of language education. In section two, the paper critically discusses and assesses the three major paradigms; interpretivism, positivism and postpositivism. In section three, the paper briefly discusses the findings and his own experiences. The paper achieved by focusing on self-reflection and tries to answer the following main research questions:

1. What are the difficulties that English major $4^{\text {th }}$ year students face in their research papers?

2. What are the most significant strategies of research methods to make students effective in their research writing?

\section{Research Objectives:}

The study ultimately aims to:

- Identify the most common difficulties that $4^{\text {th }}$ year students face while writing their research papers.

- Explore the impact of a comprehensive understanding of research methods with reference to language education.

\section{THE CONCEPTS OF ONTOLOGY AND EPISTEMOLOGY}

This section has two aims: 1 ) reflections on the idea of $4^{\text {th }}$ year students experience in educational research methods. 2) A discussion on the concepts of ontology and epistemology and their relevance to our understanding of theoretical assumptions. It is vital to place the methodologies within an ontological position and the epistemological as both affect how the methodologies are addressed. The reflections of the underpinning research methods in HE and identify the most difficulties that face students from the $4^{\text {th }}$ year within their research papers that come from the researcher of this paper own experience when he has been teaching in higher education in the UK and in Iraqi Kurdistan Region. Thus, the first reflection which is significant for the $4^{\text {th }}$ year students should be the first question that must be asked in effect what my view of reality is, what is real and what is not? According to Guba (1990, p.34), paradigms can be characterized through their ontology (what is reality), epistemology (how do you know something?) and methodology (how do go about finding out?). Thomas (2009, p.83), points out that ontology is the starting point of all research, after which one's epistemological and methodological positions logically follow. 


\section{A. Ontology}

Ontology has been defined by Thomas $(2009$, p.85) as: “...a study of what there is or what exists in the social world". While ontology as a general subject is concerned with the being of anything, here we are concerned with the ontology of human beings. According to Gronn, (1999, p.38), specifically, we are concerned with the ontology of research and methods (the nature and function of being a researcher and the actions of effective research). As stated by Thomas (2009, p.98), the starting point for interpretive researchers is to operate within a set of distinctive principles regarding what it means to conduct educational research with people. Thus, the world of the educational researcher is different from the world of the natural science researcher as all educational research needs to be grounded in people's experience. For the interpretivist reality is not out there as a combination of external phenomena waiting to be uncovered as facts, but a construct in which people understand reality in different ways.

\section{B. Epistemology}

Epistemology is defined by Thomas $(2009$, p.75) as “...what they think and how they form ideas about the world; how their worlds are constructed". In short, claims about how what is assumed to exist can be known. Derived from the Greek words episteme (knowledge) and logos (reason), epistemology focuses on the knowledge gathering process and is concerned with developing new models or theories that are better than competing models and theories Blaikie (2000, p.35). Consequently, together, ontological and epistemological assumptions make up a paradigm.

This study has found from literature review there are three contrasting epistemological positions that are those contained within the research paradigms; positivism/post-positivism and interpretivism. It is clear that choosing one of these epistemological positions will lead the researcher to employ a different methodology than he/she would if he/she chose the other. Accordingly, to know this by combining qualitative and quantitative methods that the researcher set up/ interviews/ sending out numbers of questionnaires to get statistical data. Hence, the ways in which knowledge is dependent on the methodology and it has a direct link to the strength of the claim to now knowledge.

\section{The account of research methodology and methods}

Generally speaking, in research within HE and particularly the $4^{\text {th }}$ year students, there are varieties of research methodologies with no single accepted research methodology applicable to all research problems. Hence, each research methodology has its weaknesses and strengths. According to Creswell (2007, p.238), a methodology is "the nature in which their research emerges". Conversely, educational research may be seen as twin-focused. It is a systematic enquiry that is both a distinctive way of thinking about educational phenomena, that is an attitude, and a way of investigating these phenomena, that is action or activity Blaikie (2000, p.117). In terms of a methodology, it seeks to answer the main research questions of how researchers will find out the results. Through this paradigm, the personal conflict of quantitative or qualitative or both lines of inquiry will be prominent and as with the entire positioning, the decision needs to be prudently considered. Having considered this where researchers likely to position themselves and explained the ontological and epistemological assumptions that drive their decision, it leads them to ask which research methodology.

According to Comte (2000, p.55) stated that in order to build an actionable knowledge base; three research approaches must be considered: qualitative, quantitative, and mixed methods. Unquestionably, the three approaches are not as discrete as they first appear. Qualitative and quantitative approaches should not be viewed as rigid, distinct categories, opposites, or dichotomies. Instead, they represent different ends of a continuum Newman (2000, p.77). However, mixed methods research resides in the middle of this continuum because it incorporates elements of both qualitative and quantitative approaches.

In this study, the researcher used the mixed methods as an approach to the inquiry involving collecting both qualitative and quantitative data, integrating the two forms of data, and using distinct designs that may involve philosophical assumptions and theoretical frameworks.

The next stage is to reflect the ontological and epistemological assumptions that underpin both qualitative and quantitative approaches. There is also evidence to suggest that many contemporary instances of mixture methods take place without explicitly or formally acknowledging that the practical and philosophical premises Bryman (2006, p.88). In terms of an ontological assumption, when using a mixed method approach researchers believe that there is a reality that can be understood. The researcher of this study believes this approach is useful for gaining an understanding of the research problem and the corroboration of findings. Oppositely, the research cannot simply be explained by cause and effect; it is interpreted in a variety of ways. The justification of chosen mixed methods is a logic of inquiry that includes the use of induction (the discovery of patterns) deduction (i.e. the testing of theories and hypotheses) and abduction (uncovering and relying on the best of a set of explanations for understanding one's results). This is because of its logical and intuitive appeal, this approach provides a bridge between the qualitative and quantitative paradigms (Johnson et al 1997, p.93). On the other hand, there are many advantages to using this approach in higher education. Thus, it can help the researcher to answer research questions that cannot be answered by qualitative or quantitative approaches alone Creswell (2007, p.123). Conversely, it is argued that the mixed methods approach can increase the generalizability of the results. It allows researchers to be more flexible, integrative and holistic in their investigative techniques Bryaman (2006, p.56). Accordingly, this study is a benefit for a researcher to use the epistemological assumptions to help further in order to help the decision. If a researcher will use a quantitative approach, so he/she would be independent of the research and so any relationships can be accounted for an explained, whereas with a qualitative approach there is very much being researched, essentially the findings are a result of the interactions. Hence, having decided that an exclusive mixed method is most sustainable, the strengths and weaknesses of using either qualitative or quantitative approach need to be analyzed in Higher education within Iraqi Kurdistan Region. 
Using a qualitative approach means that the social world that both the research and the participants of the research operate in can be explored. Originally, the justification for using this methodology was reflected in the hallmarks outlined by Creswell including a concern with a rich and vivid description of relevant events; focus on individual actors seeking to understand their perceptions of events Creswell (2002, p.220). Although, the combining methods have received criticism for notable lack of systematic handling of data, the weak basis for scientific generalization, lengthy completion time and the vast amount of produced documentation. As true knowing social background between two different cultures allows a researcher of this study to be more assured about research that is conducted using combined methods.

To prove this, according to Patton's (1990, p.77) claim methodology is "independent of the epistemology that gave rise to it and is related in that the epistemological position adopted constrains the type of data considered to be worth collecting and in the way that data is to be interpreted". Consequently, the mixed methods is an approach to the inquiry involving collecting both quantitative and qualitative data, integrating the two forms and using distinct designs that may involve philosophical assumptions and theoretical frameworks Robson (2002, p.45). According to Thomas (2009 p.65), one of the most advantageous characteristics of conducting mixed methods research is the possibility of triangulation, i.e. the use of several means (methods, data sources and researchers to examine the same phenomenon. Triangulation allows the researcher to identify aspects of a phenomenon more accurately by approaching it from different vantage points using different methods and techniques. Conversely, a successful triangulation requires careful analysis of the type of information provided by each method, including its strengths and weaknesses Thomas (2009, p.66). There are strengths and weaknesses to both which causes some difficulty in making a decision over with method that would ultimately choose. Acknowledging the fact that according to Bryman (2006, p.84) that "mixed methods is a new approach, but we recognize that others may not see it as a recent approach". Lastly, Creswell (2007, p.61) points out the idea that divide between the two approaches is being eroded and that both methods can be used in the same research.

\section{RESEARCH PARADIGMS: KNOWLEDGE CLAIMS}

In this section, the researcher focus is to consider the competing paradigms of educational research; that of interpretivism and positivism/ post-positivism. In order to decide on the position as a researcher in higher education, and may adopt differing ontological, epistemological and methodological assumptions that underpin each paradigm in turn or approaches of viewing by educational research in higher education.

\section{A. The Core of Interpretivism}

The definition of the interpretivism concern with subjectivity, with understanding, and the way people construct their social world introduces complexities that involve elements of uncertainty (Neuman, 2000, p.114). In interpretivism, social realities are constructed and so this paradigm is also referred to as constructivism (Guba and Lincoln, 1994, p.95). Conversely, the researcher of this study, perhaps come from an interpretivist standpoint, where a researcher record interviews about researchers or $4^{\text {th }}$ year students at the university to the epistemology (Knowledge). When a researcher of this study read the book by House (2003, p.88), thus, he understood that the reason why so many authors choose to outline positivism and interpretivism and thereby leave out a whole host of social research between these binary poles is because they can be seen as opposites: "positivists seek objectivity while interpretivist believes in subjectivity; positivists tend to model their research on the natural sciences while interpretivists believe there is a clear distinction to be made between the natural and the social world" (House, 2003, p.23).

Hence, the role of interpretivist, according to Cohen (2007, p.53), is to understand, clarify and interpret social reality through the eyes of different participants. Thus, multiple realities are therefore constructed through the eyes of different participants in the research as the same events can be perceived differently leading the conclusion of not one true answer. An interpretivist seeks to understand the question "why" moderately than explain it, unlike a positivist researcher. Dissimilar a positivist, who seeks to explain why things happen a certain way, the interpretivist will aim to explain why something can be interpreted the way it has. By regarding the epistemology of an interpretivist is that knowledge is socially constructed and not simply observed by an objective outside (Crotty et al 1998, p.34). Inside this paradigm, there exists a relationship between the researcher and that which is being researched.

Thought of this study the researcher understood that does not fit with that of a positivist, and this does not mean that the researcher can simply accept the interpretivist paradigm in educational research. The reason in arrears this that interpretivist researchers see themselves "within the circle" interpreting the world around them (Halfpenny, 2014, p.19). They have an epistemological position of that of someone cocreating and sharing knowledge, as well as creating relationships further their understanding of different points of view. As far I know, as with all the paradigms, an interpretivist standpoint has its criticisms, mainly the concept of validity and the fact that the knowledge gained from the research cannot be generalized. According to Aiken (2006, p.88), the ontological assumptions refer to the nature of reality. The positivist philosophy is objective, singular, and independent of the researcher. In contrast, the interpretivism philosophy believes reality to be subjective and multiple. Accordingly, the researcher assumed that epistemology of an interpretivist assumptions are concerned with how knowledge can be created, acquired, and communicated, in other words, what it means to know. Guba \& Lincoln (1994), p.108), they clarified that epistemology asks the question, what is the nature of the relationship between the would-be knower, what can be known? Also, I am not convinced that it is possible to rigorously test the idea that originates from the social world in order to accept them as knowledge. This is the point where I begin to question myself, I can take an interpretivist contentedly or I need to search for a paradigm that practically between the interpretivist and positivism. However, the main disadvantage associated with interpretivism relates to the subjective nature of this approach and great room for bias on behalf of the 
researcher. Primary data generated in interpretivist studies cannot be generalized since data is impacted by personal viewpoint and values.

\section{B. The Core of Positivism/ Post-positivism}

According to Comte (2000, p.41) stated that " positivism is a term with many uses in social science and philosophy and at the broad end, it embraces any approach which applies the scientific method to human affairs conceived as belonging to a natural order open to objective enquiry".

The positivist paradigm of exploring social reality is based on the philosophical ideas of the French philosopher Auguste Comte (2000, p.98), who has emphasized observation and reason as a means of understanding human behaviour. According to him, true knowledge is based on the experience of senses and can be obtained by observation and experiment. Positivistic thinkers adopt his scientific method as a means of knowledge generation. Conversely, the ontological assumptions of a positivist approach are that the reality is external to the researcher and that everything can be understood and the existence of an objective, independent and stable reality, which is available for discovery and analysis. According to Thomas $(2009$, p.78), the positivist view of the relationship between the knower and the known is one, 'objective observer'. The researcher can stand apart from that which is observed and report on the reality that is discovered through this observation. Also, as stated by Hughes and Sharrock (1997, p.66), the epistemological assumptions that in a positivist standpoint knowledge is objective and can be deduced from a theory or hypothesis. In this case, validity is sought through the fact that values and biases are diminished because of the objectivity of the researcher, which in turn leads to the notion of truthful findings. Instead, positivists argue that science can be conducted in a value-free, objective manner and a neutral process can discover a single 'truth'. Lastly, positivism was the main type of scientific inquiry for centuries, but alternative paradigms have now appeared to question whether a positivist standpoint is the best way to conduct educational research in higher education.

It is questionable whether a paradigm, which supports inquiry to be as simple and concise as possible, can be used to determine truthful findings when conducting research in the arena as complicated and broad as social sciences. It could be argued that the researcher should be adjusted to this line of thinking and using a positivist approach. As a researcher cannot fully justify either an interpretivist or a positivist standpoint, it has led him to discover what is meant a post-positivism researcher. According to Robson (2002, p.29), the division of paradigms is necessary and commendable, the term "realism is somewhat confusing, as it represents an ontological position which is shared in part by positivism and several perspectives under the label 'post-positivist". Conversely, Thomas (2009, p.79), points out that unlike the positivist paradigm, the critical paradigm posits that social science can be never truly objective or valve free. As stated by Guba and Lincoln (1995, p.56), the objective is held externally and questions can be asked with regards to how the findings compare or fit knowledge. Accordingly, the post-positivist stance is not committed to finding the truth, but instead, it is produced through discussion and discourse. However, the approach that taken by post- positivism remains one of experimentation and hypothesis testing and although the procedure has been modified from that of the early positivists, they remain essentially the same. To conclude, according to Comte (2000, p.48), points out, the main criticisms being that it is difficult to ascertain what our beliefs and what are false beliefs, because participants will have their own opinions of what believe and believe they are right.

In summary of the reflection, as a researcher of this study, I like statistics, tangible, observable things and operationalizing a variable. More than once I have called a positivist. However, I do not consider myself a positivist. If I call myself a positivist, then people might expect me to only look for objective reality, only look at numbers and statistical trends and miss the beauty of the detail. Additionally, I believe the truth is socially constructed. People's subjective perceptions are a valuable source of information, not only to themselves but to the world. Thus far, I do not consider myself an interpretivist either only. I am a pragmatist. I focus on what works. I have used mixed methods and I can understand truth as a tentative, evolving entity. It is at this point resonates with me to refer to mixed methods research as a form of research. Although it is a pragmatic approach to exploring research questions, there is still a tendency amongst mixed methods researchers to claim that this approach (Firm, 2000, p.34p).

\section{Methodology}

To practically answer the main research questions of this study, and further prove the importance of research methods in higher education among $4^{\text {th }}$ year students, this study is conducted and on 20 students at the $4^{\text {th }}$ year to statistically demonstrate the most of the difficulties that students faced in selecting research methods on their final projects.

\section{Design of the study}

This study has used mixed methods of data collection; interview and questionnaire. These are two useful approaches for this study because the researcher could obtain acceptation by only seven candidates to be interviewed and this is not sufficient data to be collected for this study. Thus, a researcher had to choose a questionnaire for the rest of 13 candidates. The selected students were divided up into two groups; first group (A) they were interviewed. A researcher used structured interview because it usually deprives researchers from the opportunity to "add or remove questions, change their sequence or alter the wording of questions" (Kyale, 1998, p.18). A second group (B) they have only accepted questionnaire. Self-completion questionnaires are those that respondents can fill out on their own, saving time and money. Both methods of data collection used in this study asked the same questions. Data were collected first using the interview and the second questionnaire.

\section{Participants}

For this study, $4^{\text {th }}$ year 20 students were optionally selected from the University of Human Development in Iraqi Kurdistan Region. The students were at the $4^{\text {th }}$ year from the UHD who were taking the final project in the department of English in the academic year 2018-2019. 7 students were males while the other 13 students were females. 


\section{Procedures for data collection and analysis}

This study applied action research in order to investigate the significance of research methods with reference to language education in higher education. Action research is used because it reflects the method that helps lecturers and students to examine, an explore aspect in research methods learning in order to take action and make improvement in both their practice and their students learning the outcome.

Hence, this study aim to considering points for research methods in higher education and particular $4^{\text {th }}$ year students by putting students' stories at the centre of teaching about research methods processing. The study started at the beginning of the final year of the $4^{\text {th }}$ year students of the academic year 20182019. The students were informed that they are participating in research with this aim, and they were through an ongoing process of reflection and refinement, this approach helps students and lecturers expand their understanding of research methods and particular mixed methods in a way that is practical, accessible and innovative in their future.

\section{THE FINDINGS}

This section presents the data analysis techniques used to examine the significance of research methods in higher education. Each research question is addressed in turn to respond to the substantive and issues identified in the literature review and methodology. By doing so, a framework to reflect the new knowledge gained in addressing the research questions. Therefore, for identification, the seven candidates' interviews were referred to as A1, A2, A3, A4, A5, A6, and A7. Despite the fact, the 13 candidates for questionnaire were identified $\mathrm{B} 1$ up until B13.

Research question 1: What are the difficulties that English major $4^{\text {th }}$ year students face in their research papers?

The findings in (table), show that seven challenges are the most difficulties that facing students from the $4^{\text {th }}$ year at university in their research papers.

TABLE 1

The SEVEn Research Challenges

\begin{tabular}{|l|c|}
\hline The seven research challenges & Total $(\mathbf{n = 2 0})$ \\
\hline Choosing the right topic & 17 \\
\hline Choosing the right methodology & 15 \\
\hline Finding Study Participants & 18 \\
\hline Sources: choosing and finding the right ones & 19 \\
\hline Guide to research supervision & 17 \\
\hline Dealing with Analysis Data & 16 \\
\hline Finding the right supervisor & 18 \\
\hline
\end{tabular}

The above table is regarding the first research question that seven research challenges were identified. First is choosing the right topic, the majority (17out 20) students responded they had an issue to choose the right topic as the beginning of starting their research papers. The second challenge is choosing the right methodology, and 19 out of 20 students were facing difficulties to choose the right methodology. This is related it the literature review according to Thomas (2009, p.89). He recommends refraining from choosing between a qualitative or quantitative or mixed method and this determine what kind of design and methodology can best answer the main research questions.

The third research challenge shows from the table is finding study participants. They were 18 out of 20 students found difficulties to get acceptance from the participants to take part in their study.

A2 mentioned that "I was very nervous, but I went ahead anyway and contacted two researchers and one of them turned out to be a very key advocate in my research, he explains. "If I had listened to my fear, I never would have gotten 45 of my participants. His advice; just go for it, the worst thing that can happen is that people can say no". Questionably, A6 pointed out a similar problem of $\mathrm{A} 2$.

The fourth challenge is how to find sources and choosing the right ones. The majority of participants have mentioned this research challenge, which is 19 out of 20 students. A5 has stated, "Finding the right sources for my topic area one of the most challenging issues that I have ever faced". Oppositely, B9 has pointed out that "I was very upset when I went to the university library and I wasn't able to find any sources relate to my topic". On the other hand, a guide to research supervision is another challenging for the researchers. As it shows from the table above 17 out of 20 students' complaints against the right person should be a candidate before they started their project. This means the research supervision should be selected before starting of the final semester of $4^{\text {th }}$ stage students by the heads of college appropriately. Furthermore, 16 out of 20 participants responded that dealing with data analysis is one the most challenging research and they haven't got any basic knowledge about it. Thus, this is a huge challenging for the $4^{\text {th }}$ stage students in the final semester. Lastly, 17 out 20 participants' that they wish and hope to have a different supervisor and this means the majority of students assumed they haven't got a right supervisor based on their topic areas. See chart 1 below.

CHART 1

The SEVEn Research ChaLlenges

\section{THE SEVEN RESEARCH CHALLENGES}

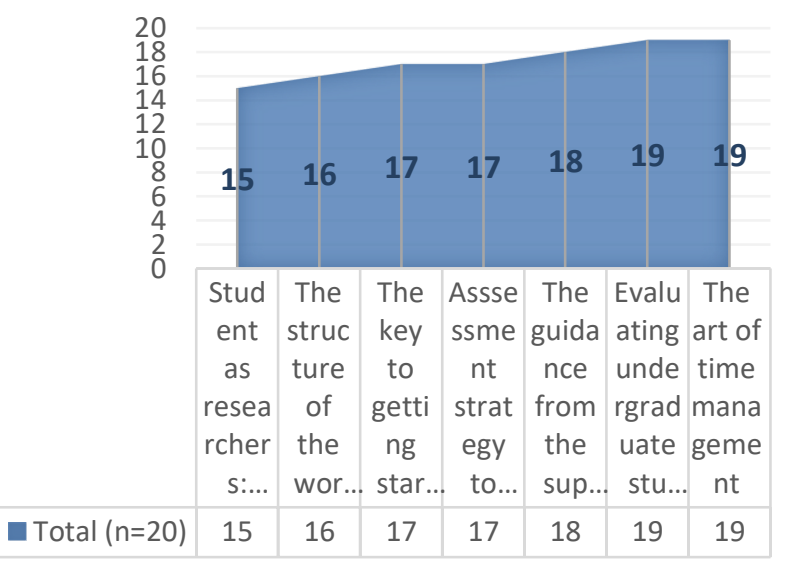


Research question 2: What are the most significant strategies of research methods to make students effective in their research writing?

The findings in (table 2) show that there are several significant impacts on research to make undergraduate students effective in their research in the final semester. From below table 2 and chart 2, it becomes clear that several significant impacts supporting undergraduate students in the disciplines at the university.

TABLE 2

THE MOST SIGNIFICANT IMPACT IN RESEARCH TO MAKE UNDERGRADUATE STUDENTS EFFECTIVE

\begin{tabular}{|l|c|}
\hline $\begin{array}{l}\text { The most significant impact in research to } \\
\text { make students effective in their research }\end{array}$ & Total $(\mathbf{n = 2 0 )}$ \\
\hline The structure of the workshop & 16 \\
\hline The guidance from the supervisors & 18 \\
\hline The art of time management & 19 \\
\hline The basic concepts of research methods & 20 \\
\hline The key to getting started in research & 17 \\
\hline $\begin{array}{l}\text { Student as researchers: supporting undergraduate } \\
\text { students in their research in the disciplines in } \\
\text { Higher Education }\end{array}$ & 16 \\
\hline $\begin{array}{l}\text { Evaluating undergraduate students as vehicles in } \\
\text { the assessment }\end{array}$ & 19 \\
\hline $\begin{array}{l}\text { Assessment strategy to evaluate individual } \\
\text { student }\end{array}$ & 18 \\
\hline
\end{tabular}

Additionally, from the above table the majority of participants, 16 out of 20 responded the structure of the workshops weren't sufficient and appropriately to link it with the basic concepts of the research methods. Conversely, 18 out of 20 responded they weren't happy with the guidance from their supervisors and this means if they were correctly guidance by their supervisors, so they could impact in their research to make them effective.

A7 mentioned, "I believe we have the tangible problem with the art of time management in doing our research paper and the main issue that we faced at the started, we haven't got the basic concepts of the research methods at all". B12 similarly stated, "at the beginning of the final semester, we haven't got the basic knowledge about research paper and the key to getting started in our final research project".

Besides this, A4 pointed out that "there isn't the structure of the workshop at the beginning of the final semester of the academic year 2018-2109". . This research paper achieved that supporting undergraduate students is vital to impact in their research papers. Moreover, 16 out of 20 participants responded they weren't sufficient supporting students in their research in the disciplines at university. Instead, 19 out of 20 responded if there were evaluating as vehicles in assessment feedback, so it supports us as students to have assessment strategy to evaluate the individual student in our groups as an undergraduate student in the final semester.
CHART 2

THE MOST SIGNIFICANT IMPACT IN RESEARCH TO MAKE UNDERGRADUATE STUDENTS EFFECTIVE

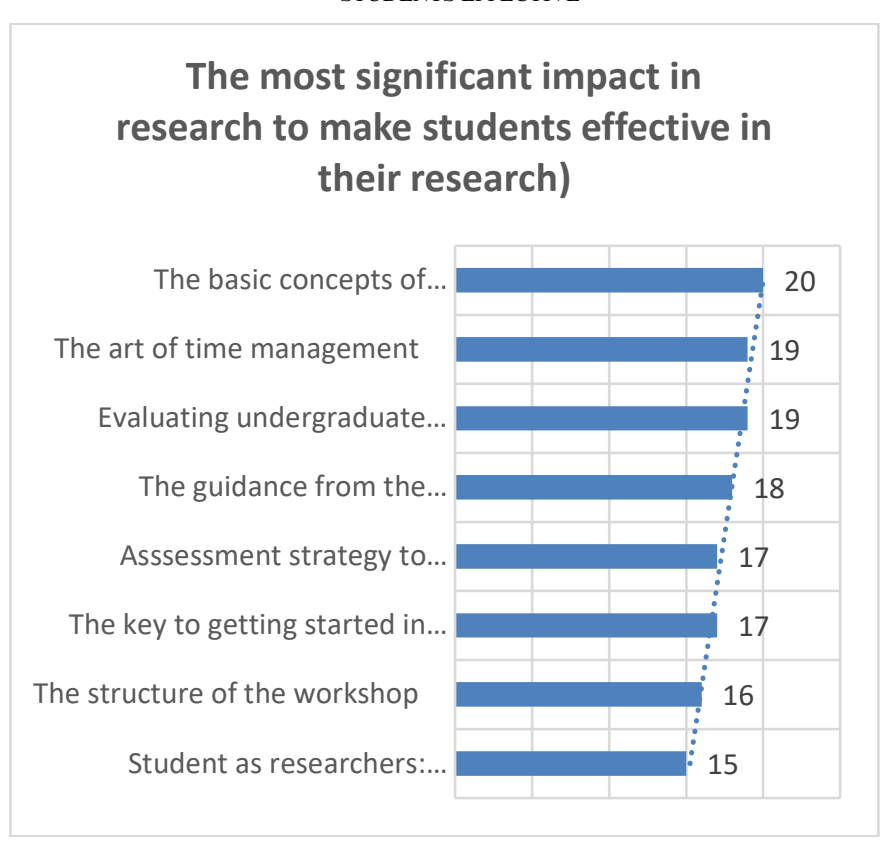

From the above chart, it becomes clear that the most significant impact in research to make students effective are the basic concepts of research methods (19 out of 20), the direct guidance from the supervisors (19 out of 20), the key to getting started in research (17 out of 20) and assessment strategy to evaluate individual students, not as a group (17 out 20). Moreover, A3 mentioned that "I have argued that my selfreflection to define my theoretical frameworks and which research methods is beaten suits myself as a student/researcher"

Additionally, B8 stated: "I assumed that we have several problems at the beginning of the stated of the final semester such as; the basic knowledge of research methods, the correct guidance from our supervisor, not getting feedback promptly".

Furthermore, A6 pointed out: "In my view, it's based on my experience, there are several important impacts in study research to make us as final year students, for example; we have to focus the art of time management during the final project, also, individually we have to consider while we are students".

A3 claimed similarly to A6: "In my view, the most vital key points that to make us effective during our research are; the correct guideline from our supervisor, we didn't have basic knowledge on the research methods".

\section{Self- Reflections}

To conclude, it is vital to reflect as a researcher of this paper, which the ontology and epistemology to decide upon the methodologies used in this research paper. As stated by Cohen (2007, p.76) the role of "the inerpretivist is to understand, clarify and interpret social reality through the eyes of different participants". Likewise, it is methodology looks to identify the socially constructed patterns and regularities of the world. Interpretivist ideas originate from Luchmann (1966) and Guba and Licoln (1985). 


\section{CONCLUSION}

In conclusion, the researcher briefly discussed the justification of the topic as a research method in the educational sector in $\mathrm{HE}$ within the Iraqi Kurdistan Region. Additionally, the researcher argued the concepts of ontology and epistemology and their relevance to our understanding of theoretical assumptions in the research methods. Furthermore, the researcher discussed the justification of the choice of methodologies and methods that I have used in this research paper. This allows a researcher to gain an understanding of the research problem and corroboration of finding. Oppositely, the researcher has critically discussed the three major paradigms; interpretivism, positivism and postpositivism. The justification of philosophical position as an interpretivist researcher, as well as partially positivist, thus, the researcher of this paper focus on what works and the value of objective and subjective knowledge. Finally, the researcher pointed out to settle on a final position of used mixed methods. Lastly, the findings show that most of the students are almost have the same problems and they have similar views on their final project. For example, table 1 and chart 1 explained the seven challenging research. Finally, from table 2 and chart 2, it becomes clear that there are several significant impacts that supporting students of the final semester to make them effective on their research papers in the disciplines at the university.

\section{REFERENCES}

Aiken, L. (2006). The landscape of qualitative research: Theories and issues. Falmer Press Teachers' Library.

Bryman, A. (2006). Quantity and Quality in Social Research. London: Routledge. First published in 1988

Bottery, M. (2004). The Educational Leadership and Theory to Practice. 1st edition. London Sage.

Babbie, E. (1998). Survey research methods. 2nd ed. Belmont: Wadsworth. Blaikie, N (2000). Design Social Research, Cambridge, Polity Press.

Comte, R. (2000). The Art of Case Study Research: Perspective in Practice. Sage, London: Educational Research Journal 32: 21-179.

Crotty, M. (1998). The foundations of social research: Meaning and perspective in the research process. 1st edition. London Sage.

Creswell, W. (2007).Research design. Qualitative, quantitative and mixed method approaches. Chapter 11: Mixed methods procedures, pp. 208-227

Creaven, H. (2007). Mixed Methods research: A research paradigm whose time has come. Educational Researcher, 33(7): 14-26.

David, K. (1984).Research design: A qualitative and quantitative, and mixed method approaches. 2ND, edition. Thousand Oaks. Sage.

Firm, J. (2000). History and Social Studies-Methodologies of Analysis Data. 1st edition. Amsterdam

Guba, E. G., \& Lincoln, Y. S. (1994). Competing paradigms in qualitative research. In N. K.

Gronn, P. (1999).The Making of Educational Leaders London: Cassell. 1st edition. London: Paul Chapman Publishing.

House, E. (2003). Realism in research. Educational Researcher, 1st edition. London: Paul Chapman Publishing. 20(6), 2-25.

Halfpenny, P. 2014. Positivism and Sociology (RLE Social Theory): Explaining Social Life, Routledge.

Hughes, G. and Sharrick, D. (1997): Research and the Teacher, Second edition London, Routledge.

Jeff, D. (2003). Educational leadership and instructional improvement in FE.1st edition. New York: Random House.

Johnson, G. (1997). Qualitative methods and analysis in organizational research. Thousand Oaks, CA: Sage.

Kayle M. (1998). Meta-Ethnography: Synthesizing Qualitative Studies. 1ST edition. Open University Press; London: Sage
LeCompte, F \& Schensul, K. (1999).Comprehensive criteria to judge validity and reliability of qualitative research within the realism paradigm. Qualitative Research, 3(3). 1st edition New York: Free Press.

Manen Van. (1995). On the epistemology of reflective practice Teachers and Teaching: Theory and Practice, (pp.33-50).

Newman, K. (2000). Action research in education: addressing gaps in Ethical principles and practices. Educational Researcher, 36(7), 400-407.

Pope, C (2007). Synthesizing qualitative and quantitative in social research: a guide to methods. 2nd edition. Open University Press, London.

Robson, J (2002).Research Synthesis in Education. 2nd edition. University of London. London: SAGE.

Patton, M. (1990). Qualitative evaluation and research methods. 1st edition. SAGE Publications, Inc.

Ritchie, J \& Spencer, K (1994). Qualitative evaluation and research methods. 3rd edition. Thousand Oaks: Sage

Saunders, C. (2012). Qualitative research requires quality concepts of its own. Management Decision, 39(7), (pp.451-555). London: Sage

Thomas, G. (2009) How to do Your Research Project.2nd edition. London: SAGE.

Yin, K. (2009). Case Study Research: Design and Methods. 2nd edition, Newbury Park, CA: Sage

Thomas J, Harden A. (2008) Methods for the thematic synthesis of qualitative research in systematic reviews. BMC Research Methodology; 2nd edition. Harlow: Pearson Education.

Walcott, K. (2011).Qualitative and quantitative methods. An introduction to theory and methods. 3rd edition. London. Sage. 